American Journal of Biochemistry and Biotechnology 4 (2): 114-120, 2008

ISSN 1553-3468

(C) 2008 Science Publications

\title{
Detection of IL-17 and IL-23 in Plasma Samples of Children with Autism
}

\author{
${ }^{1}$ Amanda Enstrom, ${ }^{1}$ Charity Onore, ${ }^{2}$ Irva Hertz-Picciotto, ${ }^{3}$ Robin Hansen, ${ }^{4}$ Lisa Croen \\ ${ }^{5}$ Judy Van de Water and ${ }^{1}$ Paul Ashwood \\ ${ }^{1}$ Department of Medical Microbiology and Immunology and the M.I.N.D. Institute \\ University of California at Davis \\ ${ }^{2}$ Department of Public Health Sciences, Division of Epidemiology, University of California at Davis \\ ${ }^{3}$ Department of Pediatrics and the M.I.N.D. Institute, University of California at Davis \\ ${ }^{4}$ Division of Research, Kaiser Permanente Northern California, Oakland, CA \\ ${ }^{5}$ Division of Rheumatology, Allergy and Clinical Immunology, University of California at Davis
}

\begin{abstract}
Interleukin-23 (IL-23) is a survival factor for a newly described population of $\mathrm{T}$ lymphocytes, namely Th-17 cells, that secrete IL-17, tumor necrosis factor- alpha (TNF $\alpha$ ) and IL-6. It has been shown that Th-17 cells are a pathogenic $\mathrm{T}$ cell subset involved in autoimmune and chronic inflammatory diseases. Based on the increasing evidence of immune dysfunction in autism, including possible autoimmune and inflammatory processes, we hypothesized that Th-17 cells, a T cell lineage that has not been previously examined in this disorder, may be altered in autism. To assess the potential role, if any, of Th-17 cells in autism, we analyzed plasma samples obtained from children ranging in age from 2-5 years with a diagnosis of autism and age-matched typically developing controls for the presence of IL-17 and IL-23 cytokines. Plasma samples from 40 children with autism including 20 children with a regressive form of autism, 20 with early onset and no regression and 20 typically developing age-matched control children were analyzed for IL-17 and IL-23, under the hypothesis that altered number and function of Th-17 cells would directly correlate with altered levels of IL-17 and IL-23 in the plasma. In this study, we were able to demonstrate that IL-23 cytokine levels were significantly different in children with autism compared with age-matched controls, a finding primarily driven by children with early onset autism. In contrast, there were no statistical differences in IL-17 levels autism compared with age-matched typically developing controls. This is the first study to report altered IL-23 production in autism. The decreased plasma IL-23 production observed in children with autism warrants further research as to its affect on the generation and survival of Th-17 cells, a subset important in neuroinflammatory conditions that may include autism.
\end{abstract}

Key words: Autism, Th-17 cells, inflammation, IL-23, neurodevelopment

\section{INTRODUCTION}

Autism (AU) is a neurodevelopmental disorder presenting in early childhood with specific social and behavioral abnormalities. Autism is generally evident by 3 years of age. A regressive form of autism has been described for children who meet early developmental milestones up to 12-18 months of age but then lose acquired speech and/or social skills. The occurrence and timing of regression has led to an interest in early life infectious and environmental exposures that occur within this same period and have been hypothesized to play a role in the genesis of autism disorder. To date, no concrete evidence for a direct causative early life exposure has been defined. However, many researchers have described various immunological abnormalities in subjects with autism, specifically in levels of inflammatory mediators and autoimmune responses ${ }^{[1-3]}$. This suggests that the immune system in some children with autism may be dysregulated. The neuroimmune hypothesis of autism suggests that these dysregulated immune responses either directly or indirectly adversely affect the course of neurodevelopment in the brain, leading to the development of autism ${ }^{[3]}$. Immune abnormalities include increased inflammatory cytokines in the plasma and CNS, specifically neuroinflammatory cytokine interleukin-6 (IL-6) $\left.{ }^{[4,} \quad 5\right]$, proinflammatory cytokine tumor necrosis factor alpha $(\mathrm{TNF} \alpha)^{[4-6]}$ and chemoattractant cytokine macrophage chemotactic protein-1 (MCP-1) ${ }^{[7]}$. Despite this evidence, a clear role for the inflammatory process in the pathogenesis of autism has yet to be defined.

Corresponding Author: $\quad$ Dr. Paul Ashwood, Department of Microbiology and Immunology and the M.I.N.D. Institute, $280550^{\text {th }}$ Street, Wet lab building, Sacramento, CA 95817 
In recent studies, a distinct subset of $\mathrm{T}$ helper cells (Th-17) has been described that are unique from the traditional paradigm of Th1 and Th2 cells. For more than 30 years, CD4+ T-helper cells have been divided into two main subsets, Th1 and Th2 cells, based on their cytokine production patterns and biological effects. Th1 cells are associated with an antiintracellular pathogen-driven cell-mediated immune response, produce interferon-gamma (IFN $\gamma$ ) and IL-2 and are long thought to initiate and mediate tissue damage. Conversely, Th2 cells are efficient at directing primarily humoral responses against extracellular pathogens and produce IL-4, IL-5 and IL-13. In contrast, Th-17 cells are characterized by their production of IL-17 in response to the cytokine IL- $23^{[8,}$ 9] and produce a distinct pattern of cytokines, including IL-17, IL-6, TNF $\alpha$ but not IFN $\gamma$ and IL- ${ }^{[9-13]}$. IL-17 production by $\mathrm{Th}-17$ cells has been associated with inflammation and development of autoimmune disease, such as chronic intestinal inflammation ${ }^{[14-16]}$, rheumatoid arthritis ${ }^{[17-19]}$ and multiple sclerosis ${ }^{[20-22]}$. Neutralization of IL-17 can decrease disease severity ${ }^{\text {[22- }}$ 24].

Further research into the Th-17 lineage has revealed that IL-23 acts as a survival factor for memory and effector Th-17 cells ${ }^{[8-9]}$. IL-23 is a heterodimer that has structural similarities with IL-12, both sharing a IL12 p40 subunit. However, IL-23 has a distinctive second subunit, p19, that is not shared with IL-12 ${ }^{[25]}$. Since IFN $\gamma$, which is increased in many chronic inflammatory and autoimmune disease models, induces production of IL-12, Th1 cells were interpreted as playing a decisive role in disease pathogenesis; however, a more pivotal role may actually be attributable to IL-23 production ${ }^{[17,26,27]}$. In co-culture cellular studies, IL-23 stimulated CD4+ $\mathrm{T}$ cells produced an increased expression of the proinflammatory cytokines IL-17, IL-6 and $\mathrm{TNF}^{[8-9]}$. Current research examining IL-12p40 compared with IL-23p19 in autoimmune disease pathogenesis revealed that disease progression was driven by IL-23 and not by IL-12 $\left.2^{[17,} 26-28\right]$. Furthermore, anti-IL-23 therapy decreases symptoms of experimental automimmune encephalomyelitis in an animal model of multiple sclerosis $^{[22]}$. With the administration of anti-IL-23 therapy, not only are IL-17 serum levels reduced, but CNS expression of IFN $\gamma$, IL-17, IL-6 and TNF $\alpha$ are also decreased ${ }^{[22]}$. Interestingly, aside from IL-23, transforming growth factor- beta (TGF- $\beta$ ), which has a modulatory effect on Th1 and Th2 development ${ }^{[29]}$, actually increases IL-17 expression ${ }^{[10,12]}$.
Recent evidence suggests that Th-17 cells may be involved in development of autoimmune and inflammatory disease and therefore, its potential role in autism warrants investigation. Th-17 cells produce the cytokines IL- 6 and TNF $\alpha$, which have been shown to be increased in subjects with autism ${ }^{[4-6]}$. Furthermore, in one recent study, mice that were deficient in a Th-17 cell inhibitor, IL-27, developed severe neuroinflammation following infection with Toxoplasma gondii, a finding that correlated with increased IL-17 production $^{[30]}$. In this study, researchers found that IL- 6 and TGF- $\beta$ induced this IL-17 response. Furthermore, in a study using anti-IL-23p19 antibody to treat autoimmune encephalomyelitis, CNS expression of IFN $\gamma$, IL-17, IL-6 and TNF $\alpha$ were decreased ${ }^{[22]}$. Combining the neuroinflammatory role of $\mathrm{Th}-17$ cells and the apparent abnormal regulation of IL-6, TNF $\alpha$ and IFN $\gamma$ in autism, cytokines linked to Th-17 cell generation $^{[10,12,30]}$, we hypothesized that abnormal Th17 cell production may play a role in this disorder. In the current study, we examined the presence of secreted IL-17 and IL-23 in the plasma of children with autism.

\section{MATERIALS AND METHODS}

Study subjects: A total of 60 children ranging in age between 2 to 5 years of age were enrolled in the study. The participants for the study were recruited as part of the CHARGE study ${ }^{[31]}$ at the University of California, Davis. The study was reviewed and approved by the institutional review board of UC Davis. Informed consent was obtained from a legal guardian for each subject. Each participant, including general population age-matched control subjects, was evaluated at the UC Davis M.I.N.D. Institute Clinic. Autism diagnosis was confirmed for the case group using the Autism Diagnostic Interview-Revised (ADI-R) ${ }^{[32]}$ and the Autism Diagnostic Observation Schedule (ADOS) ${ }^{[33-36]}$ in order to determine eligibility for the study. The ADI$\mathrm{R}$ is a well standardized interview designed to produce a diagnostic algorithm for autism spectrum disorders using answers provided by the child's caregiver based on a child's developmental and behavioral history. The ADI-R is appropriate for patients with mental ages of two and above and is consistent with the DSM-IV and ICD-10 definitions of autism. The ADOS is a standardized behavioral observation utilizing semistructured play based interactions designed to elicit communication, social interactive and imaginary play behaviors typically impaired in children with autism spectrum disorders. Plasma cytokine levels were compared in 40 subjects diagnosed with autism (AU) 
ranging in age from 2 years 1 month to $4 y 10 m$ (mean $3 y 5 m$, 36 males) who met autism cut-off criteria on both the ADI-R and the ADOS, with 20 subjects who were typically developing (TD) ranging from $2 \mathrm{y} 7 \mathrm{~m}$ to $5 \mathrm{y} 2 \mathrm{~m}$ (mean $3 \mathrm{y} 8 \mathrm{~m}, 16$ males). The $\mathrm{AU}$ groups were further subdivided into either early onset or regressive AU, based on the behavioral information provided through the ADI-R. Individuals meeting AU criteria and who did not have a history of loss of developmental skills on the ADI-R were classified as early onset AU $(n=20$, ranging from $2 y 4 m$ to $4 y 10 m$, mean $3 y 3 m, 17$ males) and subjects who attained skills that they later lost were classified as regressive $\mathrm{AU}(\mathrm{n}=20$, ranging from $2 \mathrm{y} 1 \mathrm{~m}$ to $4 \mathrm{y} 10 \mathrm{~m}$, mean $3 \mathrm{y} 6 \mathrm{~m}, 19$ males). The typically developing controls were screened with the Social Communication Questionnaire (SCQ) ${ }^{[37]}$ for autistic behaviors and assessed for developmental status with the Mullen Scales of Early Learning (MSEL) ${ }^{[38]}$ and the Vineland Adaptive Behavior Scales (VABS) ${ }^{[39]}$. Children scored below the cut-off on the SCQ and within 2 standard deviations of the mean on both the MSEL and the VABS in order to be included in the control group.

Plasma IL-17 and IL-23 ELISA: Peripheral blood was collected in acid-citrate-dextrose Vacutainer tubes (BD Biosciences, San Jose, CA) and centrifuged for 10 min at $2300 \mathrm{rpm}$. Plasma was harvested and stored at $80^{\circ} \mathrm{C}$ until the date of assay. Plasma samples were thawed and analyzed with IL-17 specific and IL-23 specific Ready-SET-Go! Enzyme-Linked Immunosorbent Assay kits (eBioscience, San Diego, CA) using the manufacturer's protocol. Briefly, plates were coated with monoclonal antibody specific to either IL-17 or the p19 subunit of human IL-23. Either $100 \mu l$ of plasma or standard was added to appropriate wells for $2 \mathrm{hrs}$ at RT. Samples were run in duplicate. After repeated washing, the plates were incubated with biotin-conjugated detector antibody specific to IL-17 or the p40 subunit of IL-23 for $1 \mathrm{~h}$ at RT. The plates were then washed a total of 5 times before incubating for 30 min with Avidin-HRP for color development. The reaction was stopped with sulfuric acid per manufacture's protocol and the optical density determined using a Wallac Victor ${ }^{3}$ multilabel plate reader (PerkinElmer, Boston, MA) at $450 \mathrm{~nm}$. A reference reading obtained at $530 \mathrm{~nm}$ was subtracted from the optical densities. Concentration was determined by comparison of sample OD values to a standard curve. Statistical significance was determined using Student's two-tailed t-test for samples with unequal variances. Significance was accepted if $\mathrm{p}$ values were less than 0.05 .

\section{RESULTS AND DISCUSSION}

We used ELISA to quantify plasma levels of IL-23 in typically developing children (TD) and children with autism (AU). We were able to detect IL-23 in the ranges of $0.6 \mathrm{pg} \mathrm{mL}^{-1}$ to $30 \mathrm{pg} \mathrm{mL}^{-1}$. AU subjects had decreased plasma levels of IL-23 compared with TD subjects, matched for age $(p=0.037$, Fig. 1a). For AU subjects, the median with interquartile range (IQR) IL23 level was 5.05 (3.51-11.16) $\mathrm{pg} \mathrm{mL}^{-1}$ and for the TD subjects it was $12.48(3.79-17.15) \mathrm{pg} \mathrm{mL}^{-1}$. When AU subjects were subdivided based on regression, those subjects with early onset AU had significantly reduced IL-23 compared with TD controls $(p=0.002$, Table 1) However, AU with regression had similar levels compared with TD controls $(\mathrm{p}=0.126$, Table 1). Consequently, when early onset AU subjects were compared to those with regressive $\mathrm{AU}$, there were lower levels of IL-23 in those with early onset (median values $4.25 \mathrm{pg} \mathrm{mL}^{-1}$ vs. $5.78 \mathrm{pg} \mathrm{mL}^{-1}$, p=0.041, Fig. 1b, Table 1). ELISA analysis of plasma IL-17 levels revealed that there were no statistically significant differences between AU subjects and TD subjects, although there was a trend for decreased IL-17 in early onset AU (Table 1). It is important to note that the measured IL-17 levels were at the low end of the detectable range (from 0.15 to $9.19 \mathrm{pg} \mathrm{mL}^{-1}$ ) and detection may be slightly impaired by methodological restriction.

A unique subset of CD4+ T-helper cells, termed Th-17 cells, have recently been identified that produce a similar set of cytokines found to be upregulated in the blood and CNS of some subjects with autism ${ }^{[4-7,9-13]}$. Th-17 cells have been associated with several research models of autoimmune and inflammatory diseases, including multiple sclerosis, inflammatory bowel disease and toxoplasma infection ${ }^{[14-22,}{ }^{30]}$. We hypothesized that the immune dysregulation seen in children with autism could potentially be due in part to increased frequency of Th-17 cells, as evinced by increased levels of IL-17 and a survival factor for Th17 cells, namely IL-23, in the blood. To test this hypothesis, we conducted this current initial study to examine IL-17 and IL-23 plasma levels.

We have shown here that IL-23 levels were reduced in children with autism and that there was no difference in IL-17 levels in children with confirmed autism compared with age-matched typically 
a

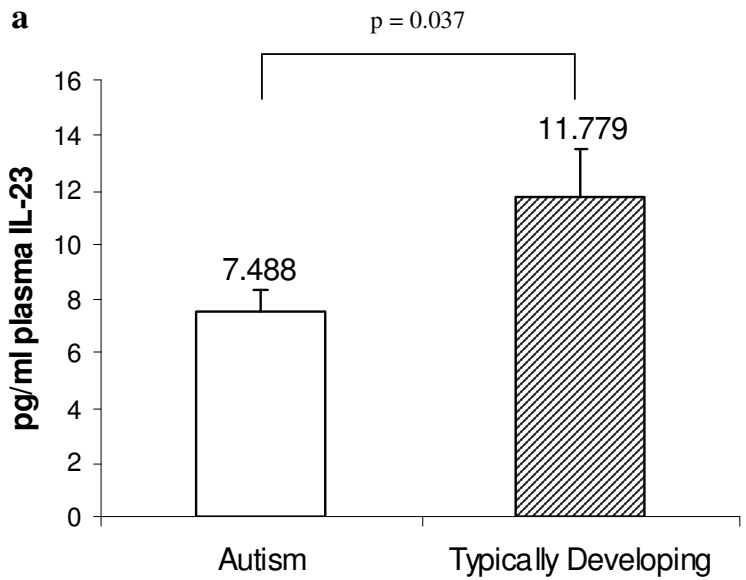

b

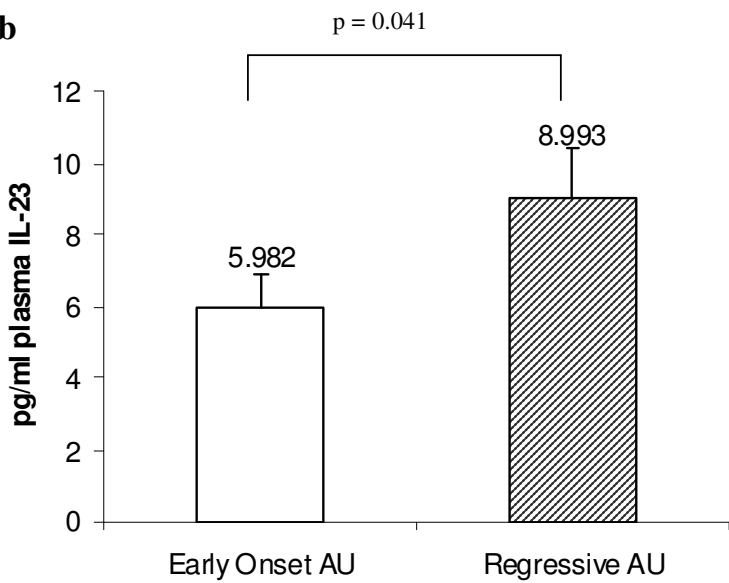

Fig. 1: Levels of IL-23 in human plasma. Quantitative ELISA analysis of plasma IL-23 in (a) children diagnosed with autism (AU, $n=40)$ compared with typically developing age-matched control children $(\mathrm{n}=20)$. Mean IL-23 values plus s.e.m. are shown. (b) Decreased IL-23 was present in plasma in children with early onset autism $(n=20)$ compared with those with regression $(n=20)$

developing control children. However, we cannot conclusively determine from this study that Th-17 cells are not dysregulated in autism subjects, only that the major cytokine produced by these cells was not dysregulated in this study population. The age of the subjects under investigation, 2 to 5 years of age, may be too young to reliably detect elevated levels of plasma IL-17. This may be reflected in the fact that IL-17 levels were consistently near the limit of detection in both cases and controls. A similar finding, in slightly older control children (mean 6 years), was observed in a pediatric burn study that used Luminex analysis to determine IL-17 levels ${ }^{[40]}$. Moreover, although our initial results indicate that IL-17 levels were comparable to typically developing subjects, this could be an artifact of the age of the study subjects and less to do with the frequency of Th-17 cells in the blood. Interestingly, while there was a strong positive correlation between IL-23 and IL-17 expression in typically developing children, there was no corresponding correlation between IL-23 and IL-17 levels in children with autism (data not shown). This may suggest that IL-23 production may not stimulate the generation and survival of Th-17 cells in individuals with autism. Recent research has revealed a potential neuroprotective and neurodevelopmental role of CNS "self"-reactive $\mathrm{T}$ cells ${ }^{[41]}$, which could potentially extend to the Th-17 subset. If this is the case, IL-23 may play an indirect role in the maintenance of neuroprotection, through its generation of Th-17 cells. A major challenge to this study may be that Th-17 cells are present at low frequency in the blood, which may negatively impact the ability to detect differences in secreted IL-17 in the plasma. Therefore, systemic levels may be less pertinent than local responses as well as the actual number and function of Th-17 cells in autism. Further ongoing studies will directly examine IL-17 expression by CD4+ T cells themselves and may yield more conclusive results. Our observation that the level of IL-23 is decreased in the blood of children with autism, in particular in subjects diagnosed with early onset non-regressive autism, may indicate that the generation and survival of Th-17 cells could in fact be altered in some children with autism. However, other cytokines such as TGF- $\beta$ that act independently of IL23 could also stimulate the production of Th-17 cells ${ }^{[10]}$.

This initial report does not rule out a possible causative role of Th-17 cells in the pathology of autism but rather raises additional questions. Indeed, the biology of Th-17 is a new field and the consequence of low frequency as well as high frequency of Th-17 has not yet been elucidated. The biological impact of decreased IL-23 in the plasma of children with early onset autism described in our study is intriguing and requires further study. Early onset autism is thought by some clinicians to have a better prognosis than regressive autism ${ }^{[42]}$. In this case, decreased production of IL-23 in the plasma of children with early onset autism may suggest a regulatory mechanism that could control the extent and severity of proinflammatory and neuroinflammatory responses demonstrated in some autism cases. More definitive research on the precise nature of immune dysregulation in early onset autism and regressive autism is needed. In this study, we have 
Am. J. Biochem. \& Biotech., 4 (2): 114-120, 2008

Table 1: Plasma IL-23 and IL-17 levels from subjects with autism and typically developing subjects. Median values plus inter quartile ranges of IL-23 and IL-17 plasma levels are shown from children diagnosed with Early onset autism (AU), Regressive AU, combined AU subjects, and typically developing (TD) subjects. IL-23 levels were significantly different between Early onset AU and typically developing subjects using Student's t-test $\left({ }^{*} \mathrm{p}<0.05,{ }^{* *} \mathrm{p}<0.005\right)$

\begin{tabular}{lcccc}
\hline & $\begin{array}{c}\text { Early onset AU } \\
(\mathrm{n}=20)\end{array}$ & $\begin{array}{c}\text { Regressive AU } \\
(\mathrm{n}=20)\end{array}$ & $\begin{array}{c}\text { Combined AU subjects } \\
(\mathrm{n}=40)\end{array}$ & $\begin{array}{c}\text { Typically Developing } \\
(\mathrm{n}=20)\end{array}$ \\
\hline Median IL-23 $\left(\mathrm{pg} \mathrm{mL}^{-1}\right)$ & $4.25^{* *}$ & 5.78 & $5.05^{*}$ & 12.48 \\
(Q1-Q3) & $(2.82-10.33)$ & $(4.01-14.81)$ & $(3.51-11.16)$ & $(3.79-17.15)$ \\
Median IL-17 $\mathrm{pg} \mathrm{mL}^{-1}$ & 1.32 & 1.78 & 1.37 & 1.81 \\
$(\mathrm{Q} 1-\mathrm{Q} 3)$ & $(1.01-1.74)$ & $(1.10-2.56)$ & $(1.06-2.36)$ & $(1.27-, 2.18)$ \\
\hline
\end{tabular}

shown for the first time that IL-23 production in autism subjects is decreased, and suggest that further investigation of this altered cytokine production may have important implications in the generation and survival of Th-17 cells, a subset of cells important in neuroinflammatory and autoimmune conditions.

\section{ACKNOWLEDGEMENTS}

We would like to thank the children and families who participated in this study. We also would like to acknowledge the staff of the UC Davis M.I.N.D. Institute and CHARGE study for their technical support and expertise. This work was funded by grants from NIEHS Children's Center grant (1 P01 ES11269-01), US EPA STAR program grant (R829388), the M.I.N.D. Institute, the Cure Autism Now Foundation, the Ted Lindsay Foundation and a generous gift from the Johnson family.

\section{REFERENCES}

1. Ashwood, P., S. Wills and J. Van De Water, 2006. The immune response in autism: a new frontier for autism research. J. Leukocyte Biol., 80: 1-15

2. Cohly, H.H.P. and A. Panja, 2005. Immunological findings in autism. Int. Rev. Neurobiol., 71: 317341

3. Korvatska, E., J. Van de Water, T.F. Anders and M.E. Gershwin, 2002. Genetic and immunologic considerations in autism. Neurobiol. Dis., 9: 107125

4. Croonenberghs, J., E. Bosmans, D. Deboutte, G. Kenis and M. Maes, 2002. Activation of the inflammatory response system in autism. Neuropsychobiology, 45: 1-6.

5. Jyonouchi, H., S.N. Sun and H. Le, 2001. Proinflammatory and regulatory cytokine production associated with innate and adaptive immune responses in children with autism spectrum disorders and developmental regression. J. Neuroimmunol., 120: 170-179
6. Ashwood, P. and A.J. Wakefield, 2006. Immune activation of peripheral blood and mucosal CD3(+) lymphocyte cytokine profiles in children with autism and gastrointestinal symptoms. J. Neuroimmunol. 173: 126-134

7. Vargas, D.L., C. Nascimbene, C. Krishnan, A.W. Zimmerman and C.A. Pardo, 2005. Neuroglial activation and neuroinflammation in the brain of patients with autism. Ann. Neurobiol., 57: 67-81

8. Aggarwal, S., N. Ghilardi, M.H. Xie, F.J. de Sauvage and A.L. Gurney, 2003. Interleukin-23 promotes a distinct CD4 $\mathrm{T}$ cell activation state characterized by the production of interleukin-17. J. Biol. Chem., 278: 1910-1914

9. Langrish, C.L., Y. Chen, W.M. Blumenschein, J. Mattson, B. Basham, J.D. Sedgwick, T. McClanahan, R.A. Kastelein and D.J. Cua, 2005. IL-23 drives a pathogenic $\mathrm{T}$ cell population that induces autoimmune inflammation. J. Exp. Med., 201: 233-240

10. Veldhoen, M., R.J. Hocking, C.J. Atkins, R.M. Locksley and B. Stockinger, 2006. TGF beta in the context of an inflammatory cytokine milieu supports de novo differentiation of IL-17producing T cells. Immunity, 24: 179-189

11. Harrington, L.E., R.D. Hatton, P.R. Mangan, H. Turner, T.L. Murphy, K.M. Murphy and C.T. Weaver, 2005. Interleukin 17-producing CD4(+) effector $\mathrm{T}$ cells develop via a lineage distinct from the T helper type 1 and 2 lineages. Nat. Immunol., 6: 1123-1132

12. Bettelli, E., Y.J. Carrier, W.D. Gao, T. Korn, T.B. Strom, M. Oukka, H.L. Weiner and V.K. Kuchroo, 2006. Reciprocal developmental pathways for the generation of pathogenic effector $\mathrm{T}(\mathrm{H}) 17$ and regulatory T cells. Nature, 441: 235-238

13. Mangan, P.R., L.E. Harrington, D.B. O'Quinn, W.S. Helms, D.C. Bullard, C.O. Elson, R.D. Hatton, S.M. Wahl, T.R. Schoeb and C.T. Weaver, 2006. Transforming growth factor-beta induces development of the $\mathrm{T}(\mathrm{H}) 17$ lineage. Nature, 441: 231-234 
14. Hue, S., P. Ahern, S. Buonocore, M.C. Kullberg, D.J. Cua, B.S. McKenzie, F. Powrie and K.J. Maloy, 2006. Interleukin-23 drives innate and $\mathrm{T}$ cell-mediated intestinal inflammation. J. Exp. Med., 203: 2473-2483

15. Fujino, S., A. Andoh, S. Bamba, A. Ogawa, K. Hata, Y. Araki, T. Bamba and Y. Fujiyama, 2003. Increased expression of interleukin 17 in inflammatory bowel disease. Gut, 52: 65-70

16. Yen, D., J. Cheung, H. Scheerens, F. Poulet, T. McClanahan, B. Mckenzie, M.A. Kleinschek, A. Owyang, J. Mattson, W. Blumenschein, E. Murphy, M. Sathe, D.J. Cua, R.A. Kastelein and D. Rennick, 2006. IL-23 is essential for T cellmediated colitis and promotes inflammation via IL17 and IL-6. J. Clin. Invest., 116: 1310-1316.

17. Murphy, C.A., C.L. Langrish, Y. Chen, C. Blumenschein, T. McClanahan, R.A. Kastelein, J.D. Sedgwick and D.J. Cua, 2003. Divergent proand Antiinflammatory roles for IL-23 and IL-12 in joint autoimmune inflammation. J. Exp. Med., 198: 1951-1957

18. Sato, K., A. Suematsu, K. Okamoto, A. Yamaguchi, Y. Morishita, Y. Kadono, S. Tanaka, T. Kodama, S. Akira, Y. Iwakura, D.J. Cua and H. Takayanagi, 2006. Th17 functions as an osteoclastogenic helper $\mathrm{T}$ cell subset that links $\mathrm{T}$ cell activation and bone destruction. J. Exp. Med., 203: 2673-2682

19. Chabaud, M., P. Garnero, J.M. Dayer, P.A. Guerne, F. Fossiez and P. Miossec, 2000. Contribution of interleukin 17 to synovium matrix destruction in rheumatoid arthritis. Cytokine, 12: 1092-1099

20. Lock, C., G. Hermans, R. Pedotti, A. Brendolan, E. Schadt, H. Garren, A. Langer-Gould, S. Strober, B. Cannella, J. Allard, P. Klonowski, A. Austin, N. Lad, N. Kaminski, S.J. Galli, J.R. Oksenberg, C.S. Raine, R. Heller and L. Steinman, 2002. Genemicroarray analysis of multiple sclerosis lesions yields new targets validated in autoimmune encephalomyelitis. Nat. Med., 8: 500-508

21. Komiyama, Y., S. Nakae, T. Matsuki, A. Nambu, H. Ishigame, S. Kakuta, K. Sudo and Y. Iwakura, 2006. IL-17 plays an important role in the development of experimental autoimmune encephalomyelitis. J. Immunol., 177: 566-573

22. Chen, Y., C.L. Langrish, B. Mckenzie, B. JoyceShaikh, J.S. Stumhofer, T. McClanahan, W. Blumenschein, T. Churakovsa, J. Low, L. Presta, C.A. Hunter, R.A. Kastelein and D.J. Cua, 2006. Anti-IL-23 therapy inhibits multiple inflammatory pathways and ameliorates autoimmune encephalomyelitis. J. Clin. Invest.,116: 1317-1326

23. Rohn, T.A., G.T. Jennings, M. Hernandez, P. Grest, M. Beck, Y. Zou, M. Kopf and M.F. Bachmann, 2006. Vaccination against IL-17 suppresses autoimmune arthritis and encephalomyelitis. Eur. J. Immunol., 36: 28572867

24. Koenders, M.I., E. Lubberts, B. Oppers-Walgreen, L. van den Bersselaar, M.M. Helsen, F.E. Di Padova, A.M.H. Boots, H. Gram, L.A.B. Joosten and W.B. van den Berg, 2005. Blocking of interleukin-17 during reactivation of experimental arthritis prevents joint inflammation and bone erosion by decreasing RANKL and interleukin-1. Am. J. Pathol., 167: 141-149

25. Oppmann, B., R. Lesley, B. Blom, J.C. Timans, Y. $\mathrm{Xu}, \mathrm{B}$. Hunte, F. Vega, N. Yu, J. Wang, K. Singh, F. Zonin, E. Vaisberg, T. Churakova, M.R. Liu, D. Gorman, J. Wagner, S. Zurawski, Y.J. Liu, J.S. Abrams, K.W. Moore, D. Rennick, R. de WaalMalefyt, C. Hannum, J.F. Bazan and R.A. Kastelein, 2000. Novel p19 protein engages IL12 p40 to form a cytokine, IL-23, with biological activities similar as well as distinct from IL-12. Immunity, 13: 715-725

26. Cua, D.J., J. Sherlock, Y. Chen, C.A. Murphy, B. Joyce, B. Seymour, L. Lucian, W. To, S. Kwan, T. Churakova, S. Zurawski, M. Wiekowski, S.A. Lira, D. Gorman, R.A. Kastelein and J.D. Sedgwick, 2003. Interleukin-23 rather than interleukin-12 is the critical cytokine for autoimmune inflammation of the brain. Nature, 421: 744-748

27. Zhang, G.X., B. Gran, S. Yu, J.F. Li, I. Siglienti, X.H. Chen, M. Kamoun and A. Rostami, 2003. Induction of experimental autoimmune encephalomyelitis in IL-12 receptor-beta 2deficient mice: IL-12 responsiveness is not required in the pathogenesis of inflammatory demyelination in the central nervous system. J. Immunol., 170: 2153-2160

28. Gran, B., G.X. Zhang, S. Yu, J.F. Li, X.H. Chen, E.S. Ventura, M. Kamoun and A. Rostami, 2002. IL-12p35-deficient mice are susceptible to experimental autoimmune encephalomyelitis: Evidence for redundancy in the IL-12 system in the induction of central nervous system autoimmune demyelination. J. Immunol., 169: 7104-7110

29. Li, M.O., Y.Y. Wan, S. Sanjabi, A.K.L. Robertson and R.A. Flavell, 2006. Transforming growth factor-beta regulation of immune responses. Ann. Rev. Immunol., 24: 99-146 
30. Stumhofer, J.S., A. Laurence, E.H. Wilson, E. Huang, C.M. Tato, L.M. Johnson, A.V. Villarino, Q. Huang, A. Yoshimura, D. Sehy, C.J.M. Saris, J. O'Shea, L. Hennighausen, M. Ernst and C.A. Hunter, 2006. Interleukin 27 negatively regulates the development of interleukin 17-producing $\mathrm{T}$ helper cells during chronic inflammation of the central nervous system. Nat. Immunol. 7: 937-945

31. Hertz-Picciotto, I., Croen L.A., R. Hansen, C.R. Jones, J. Van de Water and I.N. Pessah, 2006. The CHARGE study: An epidemiologic investigation of genetic and environmental factors contributing to autism. Env. Health Persp., 114: 1119-1125

32. Lord, C., A. Pickles, J. McLennan, M. Rutter, J. Bregman, S. Folstein, E. Fombonne, M. Leboyer and N. Minshew, 1997. Diagnosing autism: Analyses of data from the autism diagnostic interview. J. Autism Devel. Disord., 27: 501-517

33. Lord, C., S. Risi, L. Lambrecht, E.H. Cook, B.L. Leventhal, P.C. DiLavore, A. Pickles and M. Rutter, 2000. The Autism Diagnostic Observation Schedule-Generic: A standard measure of social and communication deficits associated with the spectrum of autism. J. Autism Devel. Disord., 30: 205-223

34. Joseph, R.M., H. Tager-Flusberg and C. Lord, 2006. Cognitive profiles and social-communicative functioning in children with autism spectrum disorder. J. Child Psychol. Psychiatr. Allied Disciplines, 43: 807-821

35. Lord, C, Leventhal BL and EH Cook, 2001. Quantifying the phenotype in autism spectrum disorders. Am. J. Med. Genet., 105: 36-38
36. Owley, T., W. McMahon, E.H. Cook, T. Laulhere, M. South, L.Z. Mays, E.S. Shernoff, J. Lainhart, C.B. Modahl, C. Corsello, S. Ozonoff, S. Risi, C. Lord, B.L. Leventhal and P.A. Filipek, 2001. Multisite, double-blind, placebo-controlled trial of porcine secretin in autism. J. Am. Acad. Child Adolesc. Phychiatr., 40: 1293-1299

37. Berument, S.K., M. Rutter, C. Lord, A. Pickles and A. Bailey, 1999. Autism screening questionnaire: Diagnostic validity. Brit. J. Psychol., 175: 444-451

38. Mullen, E.M., 1995. Mullen scales of early learning. Circle Pines, MN: American Guidance Services, Inc.

39. Sparrow, S.S., D.A. Balla and D.V. Cicchetti, 1984. Vineland adaptive behavior scales interview edition expanded form manual. Circle Pines, MN: American Guidance Services, Inc.

40. Finnerty, C.C., D.N. Herndon, R. Przkora, C.T. Pereira, H.M. Oliveira, D.M.M. Queiroz, A.M.C. Rocha and M.G. Jeschke, 2006. Cytokine expression profile over time in severely burned pediatric patients. Shock, 26: 13-19

41. Ziv, Y., N. Ron, O. Butovsky, G. Landa, E. Sudai, N. Greenberg, H. Cohen, J. Kipnis and M. Schwartz, 2006. Immune cells contribute to the maintenance of neurogenesis and spatial learning abilities in adulthood. Nat. Neurosci., 9: 268-275

42. Rogers, S.J., 2004. Developmental regression in autism spectrum disorders. Mental Retard. Devel. Disabilities Res. Rev., 10: 139-143. 